\title{
Performance Index: A Simple Selection Method of Appropriate Energy Storage for Specific Application
}

\author{
Hussein Ibrahim \\ InstitutTechnologique de Maintenance Industrielle \\ (ITMI), Cégep de Sept-Îles, 175 rue de la Vérendrye Sept- \\ Îles (Québec) G4R 5B7, Canada \\ hussein.ibrahim@itmi.ca
}

\begin{abstract}
The efficiency and cost of renewable power systems using intermittent resources could significantly be improved by developing low cost, high efficiency and more sustainable energy storage systems. There are various types of storage methods, some of which are already in use, while others are still in development. A comparison study between energy storage options is presented in this paper. We have taken a look at the main characteristics of the different electricity storage techniques and their field of application (permanent or portable, long-or short-term storage, maximum power required, etc.). These characteristics will serve to make comparisons in order to determine the most appropriate technique for each type of application. Based the results obtained in this study, a "performance index" have been determined for each storage technology in order to facilitate the comparison between the different storage devices.
\end{abstract}

Keywords - Energy storage; performance index; comparisons; batteries; compressed air; flywheel; hydrogen; constraints.

\section{INTRODUCTION}

Currently, the electricity production is strongly centralized and, often, a long distance away from its end users. Load levelling is initially based on the prediction of seasonal and daily needs, but also, when energy production is not sufficient, on the contribution of secondary modes like thermal and hydraulic power plants. In fact, these plants also use stored energy: water for the pumped hydro storage plants, and fossil fuels for the thermal plants [1].

Decentralized electricity production and the fast growth of fluctuating and intermittent renewable sources (wind energy, solar energy, etc.) increase the difficulty to stabilize the electric grid, mainly due to an imbalance between supply and demand. It is therefore appropriate to generate the energy, transmit it, convert it, and then store it if need be. More than ever then, the energy storage has become a necessity. But it is very complex to store electricity as this requires costly and bulky equipment.

Decentralized electrical production from renewable energy has a major inconvenient: they fluctuate independently from demand. This means that they produce high energy generation when it is not needed and produce low energy generation when it is needed. Yet, the stability of a grid is based on the

\author{
Mazen Ghandour, Sabine Saad \\ Faculty of engineering III, Lebanese University \\ Université Saint-Joseph, \\ Beirut, Lebanon \\ drmazengh@yahoo.com, sabinesaad@yahoo.com
}

balance between supply and demand, where from the demand for further development of storage devices [2].

The fundamental idea of the energy storage is to transfer the surplus of energy produced by the power plants during the weak load periods to the peak periods (Fig. 1).

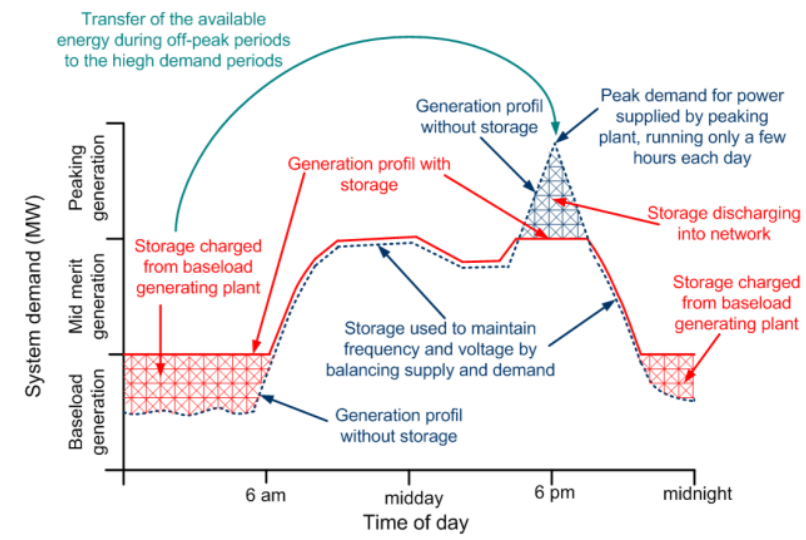

Figure 1: Principle of the energy storage

Initially, electricity must be converted into another form that can be stored (potential energy, mechanical, electrical, or chemical) and to be transformed back when needed. The stored energy should be rapidly converted on demand and used in a large variety of applications and load sizes. There exist different Energy Storage Systems (ESS) technologies; some of them are well studied and developed, while others are just emerging and waiting for new material technologies to make them cost-effective.

\section{ClASSIFICATION OF ENERGY STORAGE SYSTEMS}

There are many possible techniques for energy storage, using practically all forms of energy: mechanical, electrical, potential, chemical, and thermal. These have all been explored, leading to the birth of the techniques that will be cited herein. The energy storage technologies are many and answer to several technical and economic criteria, which vary considerably with the applications and type of needs. The comparison between these technologies is very difficult by the fact that their development levels vary greatly [3]. According to their end-uses, the energy storage systems (ESS) can be classified into four categories [4]: 
1) Low-power application in remote areas, essentially to supply transducers and emergency units;

2) Medium-power application in remote areas (individual electrical systems, town supply);

3) Grid connection application with peak sheaving;

4) Power-quality control applications.

The first two categories are for small and medium scale systems used to supply isolated regions. In these categories, the energy could be stored as compressed air, chemical energy (battery), kinetic energy (flywheel), hydrogen (fuel cells), or in supercapacitors or superconductors. Categories three and four are for large-scale systems where the energy could be stored as chemical energy (accumulators, flow batteries), thermal energy (sensible, latent), gravitational energy (hydraulic systems), or compressed air.

\section{CHARACTERISTICS OF ENERGY STORAGE TECHNIQUES}

For a specific application, it is therefore essential to analyze the technical and economic characteristics of storage systems in order to identify the comparison criteria that will be used to determine the most appropriate energy storage technology.

The principal characteristics of ESS on which the selection criteria are based are the following:

\section{A. Storage capacity}

This is the amount of energy available in the storage system after charging. Because the discharge is often incomplete, the definition of storage capacity of ESS takes into account that the total energy stored is superior to that actually recovered. The usable energy, limited by the depth of discharge, represents the limit of discharge depth (minimumcharge state). In conditions of rapid charge or discharge, the efficiency deteriorates and the recovered energy can be much lower than storage capacity. On the other hand, self-discharge is the attenuating factor under very slow regime (Fig. 2).

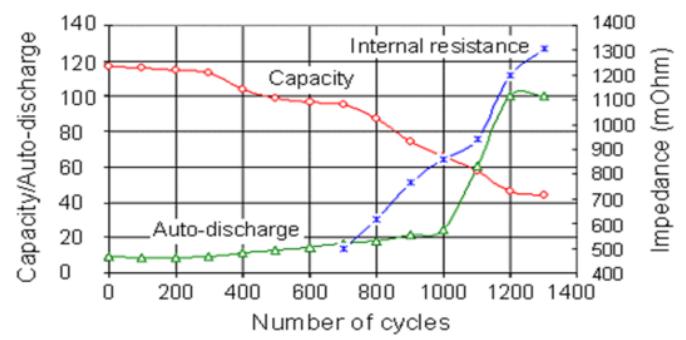

Figure 2: Technical characteristics of a nickel-metal-hydride battery [5]

$B$. Available power

This parameter determines the size of the electric component (motor/generator) in the stored energy conversion chain. It is generally expressed as an average value, as well as a peak value often used to represent maximum power of charge or discharge.

\section{Power transmission rate}

The power output or discharged power can be a limiting factor, determined by the power transmission rate. This delivery rate determines the time needed to extract the stored energy. The power must be available for delivery during peak hours. This means that the amount of energy which can be used, depends strongly on the system design, or on a fundamental limit of the storage apparatus [6].

\section{Efficiency}

This is the ratio between extracted energy and stored energy. This definition is often oversimplified because it is based on a single operation point [7]. The definition of efficiency must therefore be based on one or more realistic cycles for a specific application. Instantaneous power is a defining factor of efficiency.

\section{E. Discharge time}

This is the maximum-power discharge duration. It depends on the depth of discharge and operational conditions of the system, constant power or not.

\section{F. Durability (cycling capacity)}

This refers to the number of times the ESS can restitute, after each recharge, the energy rate it was designed. It is expressed as the maximum number of cycles $\mathrm{N}$ (one cycle corresponds to one charge and one discharge).

All ESS are subject to fatigue or wear by improper use. This is generally the main reason of aging, ahead of thermal degradation. The design of a ESS that considers the endurance of the unit in terms of cycles should be a primary importance when select a system. However, real fatigue processes are often complex and the cycling capacity is not always well defined. In all cases, it is strongly linked to the amplitude of the cycles (Fig. 3) and/or to the mean of the state of charge of ESS [8].

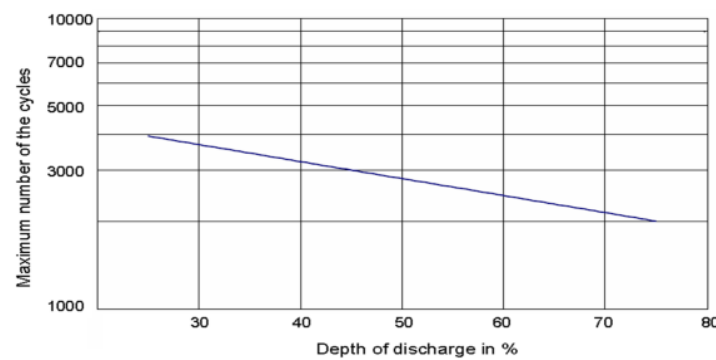

Figure 3: Variation of the cycling capacity with the depth of charge for a leadacid battery [8]

\section{G. Costs}

Like any other investment, a storage system is an interesting project when total benefits surpass total expenses. The capital invested and costs of operation and maintenance are the most important factors to take into account for the entire lifecycle of the system.

Low-efficiency systems with low cycling capacity generally require a lowest initial investment. It is therefore important to take out an analysis of the estimated durability of the entire energy generation system including the ESS [9].

\section{H. Autonomy}

This refers to the maximum amount of time the system can continuously release energy. It is defined by the ratio between the energy storage capacity and the maximum discharge power. The autonomy of a system depends on the type of storage and the type of application. 


\section{Self-discharge}

This is the part of the energy that was initially stored and which has dissipated over a given time and without any useful [10].

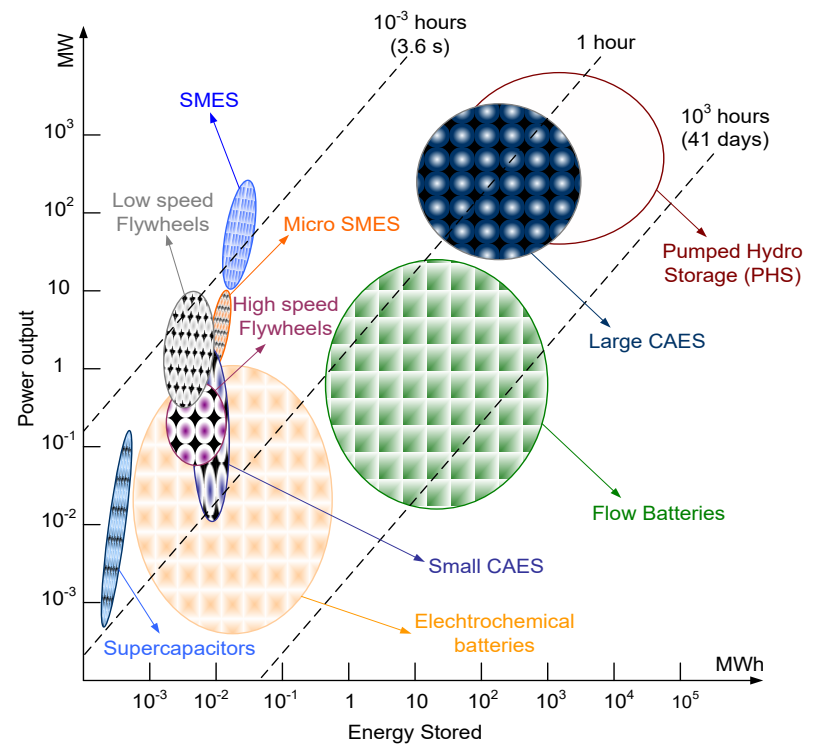

Figure 4: Repartition of the ESS according to energy needs and applications types [11]

\section{J. Adaptability to the generating systems}

To be strongly effective, an energy storage system needs to be closely adapted to the type of application (power generation in remote areas, grid connection, etc.) and to the type of production system (conventional, permanent, portable, renewable, etc.) that is meant to support (Fig. 4). In addition, the ESS must be harmonized with grid and with the entire electric system.

\section{K. Energy density}

This represents the maximum amount of energy that an ESS can be accumulating per unit of mass or volume. This parameter demonstrates the importance of the sizing of ESS (weight or volume) for certain applications especially in nonstationary applications, but less so for permanent applications.

\section{Operational constraints}

Especially related to safety (explosions, waste, bursting of a flywheel, etc.) or other operational conditions (temperature, pressure, etc.), they can influence the choice of a storage technology as a function of energy needs [8].

\section{Reliability}

Storage-system reliability is always an important factor because it is a guarantee of on-demand service [7].

\section{$N$. Monitoring and control equipement}

This equipment, on both the quality and safety of storage levels, has repercussions on the accessibility and availability of the stored energy.

\section{O. Environmental aspect}

While this parameter is not a criterion of the capacity of ESS, the environmental aspect of the product (recyclable materials) is a strong sales pitch. For example, in Nordic countries (Sweden, Norway), a important part of the population prefers to pay more for energy than to continue polluting the country [5].

\section{P. Other characteristics}

The ease of maintenance, simple design, operational flexibility (this is an important characteristic for the utility), fast response time for the release of stored energy, etc. [3].

\section{IV.CASE STUDY: CHOICE OF AN APPROPRIATED STORAGE TECHNOLOGIE FOR WIND-DIESEL HYBRID SYSTEM}

Canada is an immense country and while most of the population is concentrated near the US border, there is more than 300000 peoples living in remote sites that are not connected to the main grid of electricity. In those isolated areas, electricity is generated using diesel gensets at very high economic and environmental costs. Since most of these regions have a good wind resource, an interested solution to improve the electrification of these sites is to couple wind turbines with the diesel power plants already in place. However, in the absence of a ESS, the penetration rate of wind energy must be kept low due to the constraints related to the operation of the diesel generator. This leads to dissipate an important part of the electricity produced from the wind turbine and reduces significantly the economic interest of the hybridization between diesel and wind energy. Wind energy penetration rate can be largely increased by the addition of an energy storage system. The utilization of the excess energy allows a much more stable power and the complete stop of the diesel generators when they are not needed and a close to optimal performance of it, which reduces their maintenance cost.

The required storage system should be easily adaptable to the wind-diesel hybrid system, available in real time and offer smooth power fluctuations. It is therefore necessary to analyze the fundamental characteristics (technical and economic) of storage systems in order to establish comparison criteria and select the best technology for the high penetration wind-diesel hybrid system.

\section{A. Synthesis of the various energy storage techniques}

To compare energy storage systems, Ragone's diagram is generally used to represent their technical and economic performances with the mass or volume energy densities [12]. This type comparison is conventional and it is particularly interesting for portable applications, for which mass is a critical aspect. However, for permanent applications, life expectancy and total costs (investment, operation and maintenance costs) are the most important criteria [2]. Thus, these comparisons, overly simplistic, do not reach a definitive conclusion about the validity of the choice of appropriated energy storage to associate with a wind-diesel hybrid system. For this reason, a thorough and detailed summary will be presented in the next sections explain this selection while based on techno-economic criteria listed above.

\section{1) Electrochemical batteries energy storage (BES):}

The lead batteries are the most economical investment at 
the delivery time of the system. Unfortunately, these batteries are susceptible to misuse and have various disadvantages which need to conduct further research, especially to improve their life cycling (charging and discharging). It is in the best case, about of a thousand cycles (approximately 3 years), which is very insufficient in production systems whose lifetime is about 15 to 20 years. Moreover, the "sudden death" of lead batteries in end of life is hardly compatible with the requirements of reliable power in remote locations.

Alkaline batteries $(\mathrm{Ni} / \mathrm{Cd}$ and $\mathrm{Ni} / \mathrm{MH})$ are much more efficient, robust but more costly. They are better adapted to low temperatures and used where high reliability is required. By cons, the Ni/Cd suffers, according to the method of use, from a "memory effect" which reduces the usable capacity. Technically, lithium batteries have the best performance. Indeed, self-discharge of Li/ion is low and their stored energy density is much higher. They also allow a cycling at high deep of discharge with less impact on performance compared to the nickel/cadmium and lead batteries especially. Primarily for cost reasons, these batteries are still quite uncommon.

Finally, when the batteries are not recycled, they are a major source of pollution. For all these reasons, the batteries will not be adopted for wind-diesel hybrid system (WDHS).

\section{2) Hydrogen energy storage (HES):}

It is impossible to use hydrogen produced from wind energy as a fuel for diesel engines because they are not equipped with ignition systems. By cons, the use of the stored hydrogen to produce the electricity from a fuel cell designed to operate in the absence of wind and replace diesel for certain periods, seems a good alternative. But the poor performance of the overall electrolyzer-fuel cell $(35-40 \%)$, their unreliability, the prohibitive cost of capital and operating of this set and the safety aspect related to hydrogen storage, make sure they delay the acceptance of this technology by the market. For these reasons, the hydrogen storage will not be adopted for the WDHS.

\section{3) Flywheel energy storage (FES):}

This technology is not feasible to store large amounts of energy at long term. By cons, in the case of the supply of isolated sites, the flywheels can be used to store energy when production exceeds demand and improve the power quality where wind generation is close to the consumer level. Moreover, for a WDHS, the presence of an intermediary flywheel (by coupling the flywheel to diesel shaft) allows to reduce significantly the number of daily starts of diesel and increase the autonomy and the quality of the supplied current. Despite all these advantages, this technology has been excluded because it is a storage device for short time (a few tens of seconds to minutes) and requires, otherwise, massive materials to store energy, which increases the cost of system and of the used equipment. Moreover, this storage system will not allow a remarkable reduction in fuel consumption when the diesel functions in stand-by mode (periods of medium wind power penetration). May be added the issue of security related to the possibility of the collapse of the steering wheel.

\section{4) Thermal energy storage (TES):}

This type of storage, regardless of the technology used, can serve, using wind energy or excess heat from exhaust gases of diesel to produce hot water for heating or for use in the community where the WDHS exists. This system does not lead to reduce fuel consumption and GHG emissions. However, a better design may be offered and consists to couple the thermal energy storage (TES) to the wind-dieselcompressed air hybrid system. The TES will be used, in this case, as heat exchanger-storage device to recover the available heat in the air at the end of its compression and restore it afterwards during expansion of compressed air in the diesel engine or in an air motor. In conclusion, the TS will not be adopted as the main storage device associated with the WDHS but rather as an auxiliary system that improves the energy performance of the overall system.

\section{5) Pumped hydraulic energy storage (PHS):}

It is a large-scale storage and features a centralized production. So if it is available for remote sites, it will not be necessary to consider the use of diesel generators, especially if the wind potential is also available. By cons, storing small hydro requires abundant water resource in order to produce electricity; most of the criterion of geographical features is always present. For all these reasons, this technology has been excluded from the list of candidate technologies to be associated with the WDHS.

\section{6) Redox batteries Energy storage (RBES):}

Although the flow batteries can be used for small scale applications such as large scale, they are less mature and have yet to demonstrate their operation by hybridization with wind energy. Moreover, their prohibitive cost penalizes their integration into the market not to mention their contribution to the stopping of diesel is related to their autonomy, which also is depended to the reservoir volume of electrolytes in circulation and to the number of used cells (need large volumes and a high number of units). This increases the investment cost as well as the operating system. All these reasons exclude the possibility of adopting the flow batteries for WDHS.

\section{7) Supercapacitors energy storage (SCES):}

This type of storage is intended for small scale applications and its use at medium scale (case of WDHS) requires a series connection of several elements to achieve the required voltage. This will require more planning, more space and therefore more investment especially as the unit cost is quite high. The high self-discharge ( $5 \%$ per day), decreases the autonomy of the storage device and require a rapid consumption of wind energy stored before it is completely self-discharged without any use. This may slightly influence on the fuel consumption of diesel and its operating cost and make the overall system poorly operational and poorly harmonized. Consequently, this storage system will not be adopted for the WDHS.

\section{8) Superconducting magnetic energy storage (SMES):}

It is a storage technology for a very short duration and not feasible for medium-scale applications. Its complexity lies in 
the need for a refrigeration system, transformers and converters, and a large infrastructure. This greatly increases the cost and makes more complicate the operation of the system. Moreover, this type of storage is not too adaptable to WDHS and does not contribute to a remarkable reduction in fuel consumption. For these reasons, it is excluded from the list of the studied technologies.

After excluding all the technologies mentioned above, it is proposed to use the compressed air energy storage system (CAES) to associate with the WDHS. Indeed, the CAES is adaptable for both sources of power generation (wind / diesel). Moreover, the CAES is an interesting solution to the problem of strong stochastic fluctuations of the wind power because it offers a high efficiency conversion $(60-70 \%$ for a complete charge-discharge cycle), uses conventional materials which are easy to recycle and is able to make an almost unlimited number of cycles [3], [13].

\section{B. Validation of the choice of compressed air energy storage using the performance index method}

\section{1) Definition of the performance index}

The analysis of the techno-economic criteria such as cost, energy density, lifetime, energy efficiency of each technology, etc.., allows evaluating a «performance index» and developing a yields diagram of different storage technologies. The performance index is the measure of the applicability of a storage technique to a specified application taking into account the characteristics presented in section 6 (for example, cost, efficiency, simplicity, life time, maturity, selfdischarging, reliability, environmental impact, operation constraints, energy and power capacity, adaptability with wind-diesel system, contribution to reduce of fuel consumption, etc.) [14]. For another application than the power supply of a remote area, the values of the performance index can be different.

\section{2) Method used to determine the performance index}

The determination of performance index is done using a decision matrix that helps to balance by a factor varying from 5 to $10 \%$ the importance of each characteristic of the storage system with regard to the specific requirements of the envisaged application [15]. The development of this matrix takes into account the interaction between the selection criteria mentioned above, the reference data of storage technologies and the characteristics of WDHS and above the main objective: choice one technology that contributes to decrease the consumption fuel and GHG emissions of diesel generator.

In this study, more emphasis was given to cost, the contribution to reducing fuel and GHG emissions. A weight factor of $10 \%$ was then attributed for each of these criteria. By cons, the cyclability, autonomy, efficiency, simplicity, each has obtained a weighting equal to $7.5 \%$ for their medium importance [15]. Finally, because their lower importance, the following criteria: safety, self-discharge, storage, reliability, maturity, operational flexibility, control, and the ecological response times were weighted by coefficient of $5 \%$ for each (Figure 5).

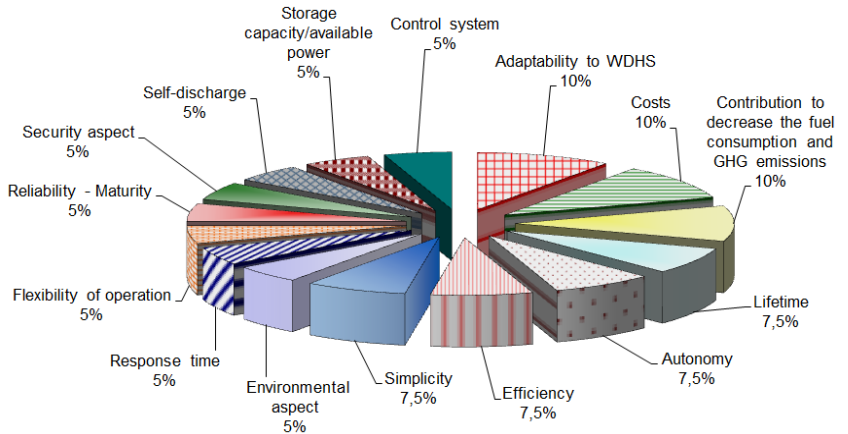

Figure 5: Allocation criteria in the decision matrix [15]

TABLE 1: ELEMENTARY DECISION MATRIX FOR THE CRITERION “ADAPTABILITY TO WDHS” [15]

\begin{tabular}{|c|c|c|c|c|c|c|c|c|c|c|}
\hline $\begin{array}{l}\text { Adaptability } \\
\text { to WDHS }\end{array}$ & $\stackrel{n}{2}$ & 忢 & 贸 & II & $\begin{array}{l}\text { ज्ञ } \\
\text { 1ै } \\
\text { ح) }\end{array}$ & 望 & 㤐 & 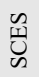 & $\sum_{i=1}^{\infty}$ & Total \\
\hline PHS & & 0 & 0 & 0 & 0.5 & 0 & 0 & 0 & 0 & 0.5 \\
\hline CAES & 1 & & 1 & 1 & 1 & 1 & 1 & 1 & 1 & 8 \\
\hline FES & 1 & 0 & & 0.5 & 1 & 0.5 & 0.5 & 0.5 & 0.5 & 4.5 \\
\hline BES & 1 & 0 & 0.5 & & 1 & 0.5 & 0.5 & 0.5 & 0.5 & 4.5 \\
\hline RBES & 0.5 & 0 & 0 & 0 & & 0.5 & 0 & 0.5 & 0.5 & 2 \\
\hline HES & 1 & 0 & 0.5 & 0.5 & 0.5 & & 0 & 0.5 & 0.5 & 3.5 \\
\hline TES & 1 & 0 & 0.5 & 0.5 & 1 & 1 & & 1 & 1 & 6 \\
\hline SCES & 1 & 0 & 0.5 & 0.5 & 0.5 & 0.5 & 0 & & 0.5 & 3.5 \\
\hline SMES & 1 & 0 & 0.5 & 0.5 & 0.5 & 0.5 & 0 & 0.5 & & 3.5 \\
\hline
\end{tabular}

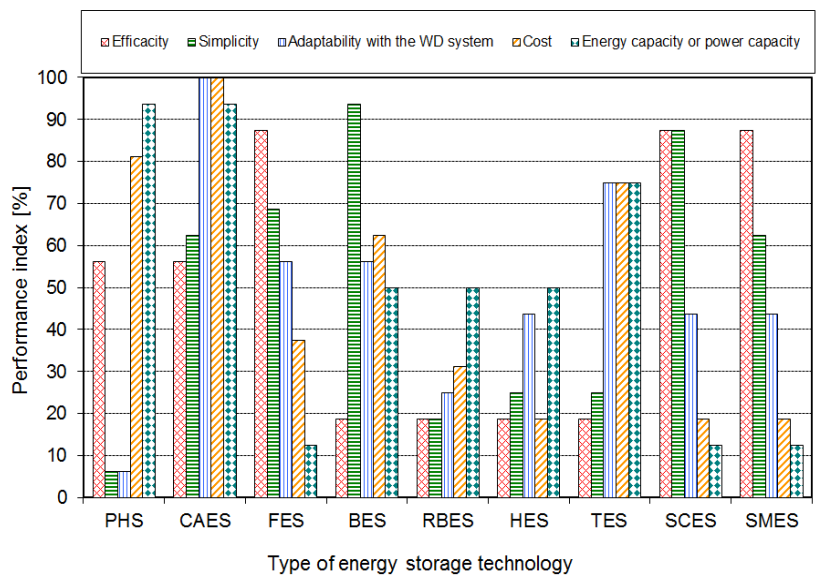

Figure 6: Comparison of the elementary performance index regarding to various criteria [15]

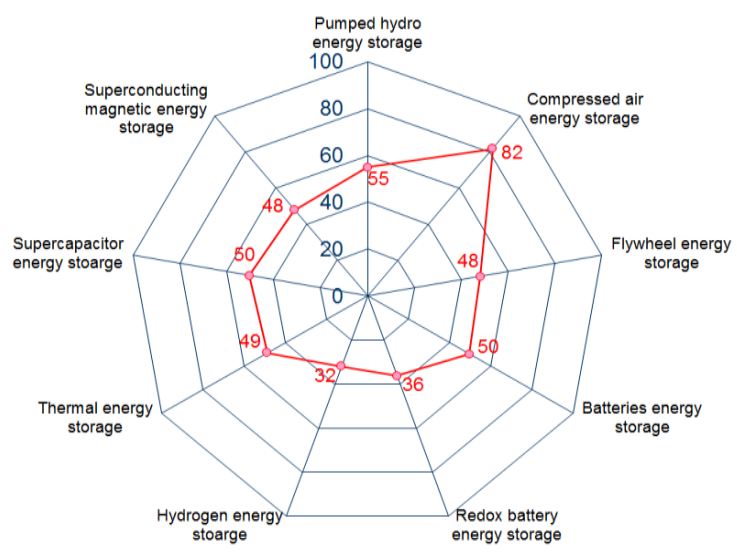

Figure 7: Global performance index of the energy storage systems 
For each criterion, we attributed a value of either $0,0.5$ or 1 to each storage technology when comparing to another, respectively if the associated performance is worse (value of 0 ), equal (value of 0.5 ) or better (value of 1 ). In Table 1, we illustrate the comparison between the energy storage technologies with regard to the adaptability to the high penetration wind-diesel hybrid system. The analysis shows that flywheel is equivalent to batteries, supercapacitors, superconducting, thermal storage and hydrogen storage (coefficient of 0.5), while it is better (more adaptable to WDHS) than hydraulic storage and flow batteries (coefficient 1) $[15-18]$. On the other hand, the compressed air storage is more adaptable to SHED compared to the flywheel; the corresponding coefficient is then 0 for flywheel. The same method is applied to all the energy storage technologies for each of the 15 selection criteria, the results being 15 elementary decision matrixes corresponding to each criterion. The global decision matrix assembles the coefficients attributed to each energy storage system for each elementary decision matrix associated to each of the 15 selection criteria [15]. Considering the weight coefficients of every criterion in the calculation, we obtained the classification of performance of each used system. The elementary performance index (Fig. 6) and overall performance index (Fig. 7) can be obtained respectively from the elementary and overall matrix of decision by calculating the percentage of the total score obtained by each technology (global) and for each mentioned criteria (elementary) compared to the maximum total score (8) that a storage technology can be obtain. It is easy to establish from the Figure 7 that the CAES answers to the choice criteria with the better performance index, approximately $82 \%$ [15$18]$.

\section{CONCLUSION}

A comparative analysis of different storage technologies currently in use was effectuated according to several criteria such as cost, energy density, specific power, contributing to reducing fuel consumption and GHG emissions, the lifetime and efficiency of each technology. This analysis was served to determine the performance index of each storage technology based on the nature of the project application. The determination of the performance index of each technology represents, despite its subjectivity resulting from the use of the decision matrix, a solution where we have some difficulty to choose a technology and where the constraint of time does not achieve a detailed modeling of the studied systems. This method, applied on wind -diesel hybrid system, showed that the CAES answers to the choice criteria with a performance index approximately $82 \%$. Other systems are also more or less effective but at the cost, simplicity, adaptability to the WDHS, the contribution to reducing fuel consumption and GHG emissions and duration of life that there is some difference. For these reasons, CAES technology was adopted to associate with the wind-diesel hybrid system.

\section{REFERENCES}

[1] www.mines-energie.org/Conferences

[2] Hussein Ibrahim, Adrian Ilinca, Jean Perron, Investigation on the Performances of Energy Storage Techniques, Reference Number CANCAM07-ETS-76, le 21ième congrès canadien de mécanique appliquée, Toronto, Canada, 3-7 juin 2007.

[3] H Ibrahim, A. Ilinca, J. Perron, Energy Storage Systems Characteristics and Comparisons, Renewable \& Sustainable Energy Reviews, May 2007.

[4] Couffin P, Perrin M. Le stockage des énergies intermittentes. Commissariat à 1'Énergie Atomique (CEA). Clefs CEA (50-51), hiver 2004-2005. p. 136-8. /www.cea.fr.

[5] Faure F. Suspension magnétique pour volant d'inertie. Thèse de doctorat. Institut National Polytechnique de Grenoble,France; Juin 2003.

[6] Buchmann I, Choisir une batterie qui aura une longue durée, Cadex Electronics Inc. Canada, /http://www.buchmann.ca.

[7] Bonneville JM. Stockage cinétique. Institut de Recherche de l'Hydro-Québec, Varennes, Québec, Canada. Rapport interne; février 1975.

[8] Gergaud O. Modélisation énergétique et optimisation économique d'un système de production éolien et photovoltaïque couplé au réseau et associé à un accumulateur. Thèse de l'ENS de Cachan; décembre 2002.

[9] Anzano J.P., Jaud P, Madet D. Stockage de l'électricité dans le système de production électrique. Techniques de l'ingénieur, traité de Génie Électrique D4030; 1989.

[10] Messenger R, Ventre J. Photovoltaic systems engineering. Boca Raton, FL: CRC Press; 1999.

[11] H. Ibrahim, A. Ilinca, J. Perron, Systèmes de stockage de l'énergie pour les éoliennes, Colloque international «Énergie éolienne et sites éloignés», Îles-de-la-Madelein, Québec, Canada, 19-21 Octobre 2005.

[12] www.electricitystorage.org

[13] H. Ibrahim, A. Ilinca, J. Perron. Comparison and Analysis of Different Energy Storage Techniques Based on their Performance Index. IEEE-Electrical Power Conference 2007, Montreal, October 25-26.

[14] H. Ibrahim, A. Ilinca, J. Perron, Investigations des différentes alternatives renouvelables et hybrides pour l'électrification des sites isolés, rapport interne, UQAR, LREE-03, 2008.

[15] H. Ibrahim. Étude et conception d'un générateur hybride d'électricité de type éolien-diesel avec élément de stockage d'air comprimé. Thèse de doctorat, Université du Québec à Chicoutimi, Août 2010.

[16] H. Ibrahim, A. Ilinca J. Perron. Solutions actuelles pour une meilleure gestion et intégration de la ressource éolienne. CSME/SCGM Forum 2008 - The Canadian society for mechanical engineering, 5-8 juin, 2008, Ottawa, Canada.

[17] H. Ibrahim, A. Ilinca, M. Ghandour, M. Dimitrova, D. Boulay, C. Arbez, M. Adegnon. Investigation des diverses options de stockage d'énergie face à l'intégration des parcs éoliens dans les réseaux. 1ère Conférence Franco-Syrienne sur les énergies renouvelables, Damas, Syrie, Octobre 2010.

[18] H Ibrahim, R Beguenane, A Merabet. Technical and financial benefits of electrical energy storage. IEEE-Electrical Power and Energy Conference (EPEC), pp. 86-91, 10 october 2012. 